\title{
Induction of chromosome shattering by ultraviolet light and caffeine: The influence of different distributions of photolesions
}

\author{
C. Cremer ${ }^{1}$ and T. Cremer ${ }^{2}$ \\ ${ }^{I}$ Institute of Applied Physics I, University of Heidelberg, D-6900 Heidelberg (Federal Republic of Germany) and \\ ${ }^{2}$ Institute of Anthropology and Human Genetics, University of Heidelberg, D-6900 Heidelberg (Federal Republic of Germany) \\ (Received 19 August 1985) \\ (Revision received 16 April 1986) \\ (Accepted 21 April 1986)
}

\begin{abstract}
Summary
Cells of synchronized and of asynchronously growing cultures of a V79 Chinese hamster line were microirradiated with a low power laser-UV-microbeam of wavelength $257 \mathrm{~nm}$. Ultraviolet light was either focused onto a small part of the nucleus (mode I) or distributed over the whole nucleus (mode II). Following microirradiation, the cells were incubated for 7-20 h with caffeine (1-2 mM) until chromosome preparation was performed. After both modes of microirradiation, shattering of the entire chromosome complement (generalized chromosome shattering, GCS) was observed. It is suggested that the probability by which GCS is induced depends on the total number of DNA lesions rather than on their distribution in the chromatin. The results are consistent with the prediction of a "factor depletion model" which assumes that in a given cell, GCS takes place both in irradiated and non-irradiated chromosomes if the total number of daughter strand-repair sites surpasses a threshold value.
\end{abstract}

In a number of cell strains, caffeine is known to potentiate the chromosome-damaging effects of ultraviolet light (Kihlman et al., 1974; Nilsson and Lehmann, 1975; Kihlman, 1977). A striking phenomenon, which is observed after whole cell irradiation with UV light $(\lambda=254 \mathrm{~nm})$ and caffeine posttreatment, is the frequent occurrence of cells with generalized chromosome shattering (GCS; fragmentation and/or pulverization of all chromosomes of a mitotic cell; Nilsson and Lehmann, 1975; C. Cremer et al., 1980a, 1981a; T. Cremer et al., 1981a; C. Cremer and Gray, 1982). Previous results (T. Cremer et al., 1980; C. Cremer et al., 1981a) obtained both with a low power laser-UV-microbeam of wavelength $257 \mathrm{~nm}$ (C. Cremer et al., 1974) and with a pulsed laser microbeam of wavelength $365 \mathrm{~nm}$ in the presence of psoralen compounds (T. Cremer et al., 1981a) showed that GCS may also be induced following microirradiation of a small part of the interphase nucleus of Chinese hamster cells and posttreatment with caffeine. Since individual interphase chromosomes have been shown to occupy relatively compact "territories" in Chinese hamster cells (Stack et al., 1977; Zorn et al., 1979; C. Cremer et al., 1980b; T. Cremer et al., 1982a; Hens et al., 1983) as well as in other mammalian cells (Rappold et al., 1984; Schardin et al., 1985) the occurrence of cells with GCS following microirradiation of a small part of the nucleus suggested that chromosome alterations may be induced not only at the sites of DNA photolesions but also at other sites.

To explain these effects a model has been pro- 
posed (T. Cremer et a1., 1980; T. Cremer et al., 1981a) which assumes that in the presence of caffeine, replication of chromatin containing numerous DNA photolesions may affect replication of undamaged chromatin (factor depletion model). This might result in breaks and/or failure of condensation also in chromatin containing no or only a few lesions.

The model predicts that the number of daughter strand-repair sites but not their spatial distribution in the cell nucleus plays a decisive role in the induction of GCS. If so, the percentage of cells with GCS should depend rather on the total incident energy than on its distribution in the cell nucleus. For this prediction, two other conditions have to be fulfilled: (a) The same number of initial DNA photolesions is produced by different distributions of energies; (b) The number of daughter strand-repair sites present at any given time after irradiation depends only on the initial number of DNA photolesions.

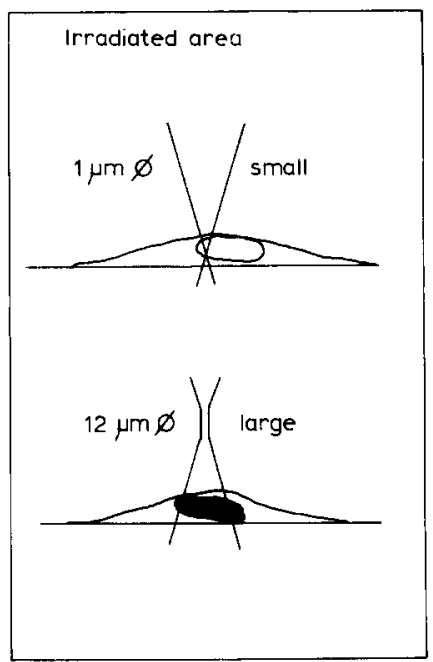

Fig. 1a. Schematic representation of the two modes of microirradiation used. Upper part: The incident UV energy is concentrated on a small part of the nucleus, the diameter at the "waist" of the beam is approximately $1 \mu \mathrm{m}$; focal plane and object plane coincide (mode I irradiation). Lower part: The incident UV energy is distributed over a large part of the nucleus, the diameter of the beam in the object plane is approximately $12 \mu \mathrm{m}$; this is achieved by adjustment of an adapting lens (C. Cremer et al., 1974) in such a way that focal plane and object plane are slightly separated (mode II irradiation)

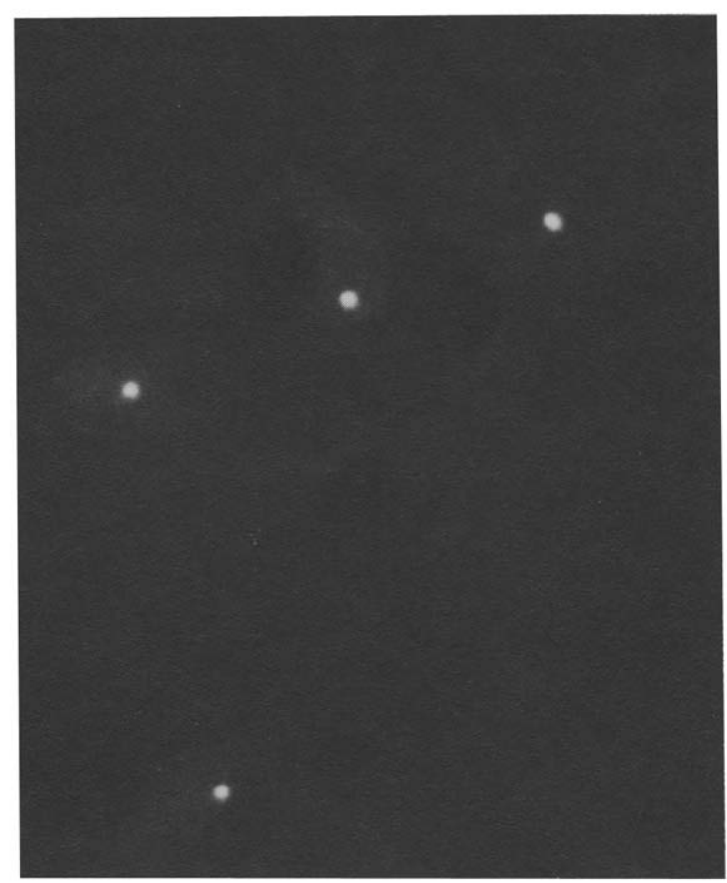

Fig. 1b. Localization of micro-irradiation sites (mode I) in the nuclei of Chinese hamster cells. Each cell was microirradiated once $\left(E_{\mathrm{inc}}=0.3 \mathrm{~nJ}\right)$. Immediately after microirradiation cells were processed for indirect immunofluorescence staining with antibodies against UV-irradiated DNA (Cornelis and Errera, 1980) as described (C. Cremer et al., 1983).

Studies by Steward and Humphrey (1966) indicate that for energy densities up to $1000 \mathrm{~J} / \mathrm{m}^{2}$, condition (a) is realized. Concerning condition (b), it has been shown both by Moreno and Salet (1974) and by our group (C. Cremer et al., 1981b) that the total amount of unscheduled DNA synthesis (UDS) depends on the total incident UV energy but not on its distribution in the nucleus (energy densities up to approximately $1000 \mathrm{~J} / \mathrm{m}^{2}$ in our experiments).

Different distributions of DNA photolesions can be realized by either focusing a UV microbeam onto a small part of the nucleus or by distributing it over the whole nucleus (Raith et al., 1984; Fig. 1). The study presented here for the first time investigates the effect of different distributions of DNA photolesions on the induction of chromosome shattering by the synergistic effect of ultraviolet light and caffeine. The results are consistent with the predictions of the "factor depletion model". 


\section{Materials and methods}

\section{Microbeam}

The laser-UV-microbeam of wavelength $257 \mathrm{~nm}$ has been described in detail (C. Cremer et al., 1974, 1976). Briefly, a coherent continuous-wave UV beam of wavelength $257.25 \mathrm{~nm}$ is focused by a Zeiss Ultrafluar objective $(32 / 0.40 \mathrm{Ph})$ which is simultaneously used for both microirradiation and phase-contrast observation. Different diameters of the irradiation field may be obtained by changing the position of an adapting lens. Thus, different distributions of a given amount of UV quanta are realized (Fig. 1). In all experiments, the UV-power incident at the cell surface was $8 \times 10^{-9} \mathrm{~W}$. Under these conditions, no "laser specific" effects (T. Cremer et al., 1981b) are expected to occur (C. Cremer et al., 1976). The time of irradiation is controlled by a photographic shutter.

\section{Cell material}

Cells of a V79 Chinese hamster subline were grown as described (C. Cremer et al., 1980a, 1981a). In these cells, caffeine potentiates the chromosome-damaging effects of ultraviolet light (C. Cremer et al., 1980a, 1981a).

\section{Microirradiation and posttreatment}

Detailed descriptions of the microirradiation procedure and the posttreatment have been given elsewhere (C. Cremer et al., 1976; Zorn et al., 1979; C. Cremer et al., 1981a, b; Raith et al., 1984). Briefly, either asynchronously growing V79 cells were microirradiated, or V79 cells were microirradiated 3-5 h after mitotic selection (referred to as synchronized cells). The incident UV energy $\left(E_{\text {inc }}\right)$ was either concentrated on a small part of the nucleus (mode I; diameter of the irradiation field approximately $1 \mu \mathrm{m}$ in the object plane) or distributed over the whole nucleus (mode II; diameter of the irradiation field approximately $12 \mu \mathrm{m}$ corresponding to the mean nuclear diameter; see Fig. 1; C. Cremer et al., 1981b).

Following microirradiation, cells were grown at $37^{\circ} \mathrm{C}$ in medium with caffeine (1.0 and $\left.2.0 \mathrm{mM}\right)$ for 7-20 $\mathrm{h}$. Then in situ chromosome preparation (Zorn et al., 1976) was performed. Colchicine (2 $\mu \mathrm{g} / \mathrm{ml}$ ) was added $3 \mathrm{~h}$ before preparation.

Mitotic cells were scored for chromosomal damage and classified according to the following criteria (T. Cremer et al., 1980; C. Cremer et al., 1980a, 1981a): Class A: no chromosomal alterations visible; Class B: single defects (one, occasionally two aberrations); Class $\mathrm{C}$ : more than two aberrations are found but the majority of chromosomes remains intact; Class D: aberrant morphology in the majority of chromosomes, only one or several chromosomes remaining intact; Class E: all chromosomes are affected (fragmentation and/or pulverization): generalized chromosome shattering (GCS). For statistical evaluation, the 95\% confidence intervals were calculated (C. Cremer et al., 1980a).

\section{Results}

(I) Microirradiation of interphase nuclei (mode I and mode II) and postincubation with $1 \mathrm{mM}$ caffeine

In these experiments, cells were microirradiated in the nucleus $3-5 \mathrm{~h}$ following mitotic selection, and posttreatment with $1 \mathrm{mM}$ caffeine was performed. Fig. 2 shows the result for $T=14 \mathrm{~h}$ incubation time and the variation of the incident UV energy. Classes C plus D were observed only in a low percentage of cases $(\leqslant 10 \%)$, while the large majority of metaphase spreads were either of classes $\mathrm{A}$ and $\mathrm{B}$, or of class $\mathrm{E}$. This result was obtained for both irradiation modes. If the percentage $P_{\mathrm{E}}$ of cells with GCS is plotted as a function of the total incident energy (abscissa " $E_{\text {inc }}$ "), the dependence of $P_{\mathrm{E}}$ on this parameter is similar for the two irradiation modes: For $E_{\text {inc }}<$ $0.03 \mathrm{~nJ}$, no cells with GCS are observed; above this value there is an increase up to $63 \%$ (mode I) and $34 \%$ (mode II), respectively. For both irradiation modes, a marked percentage of cells with GCS was obtained for incident UV energies between about 0.1 and $1.0 \mathrm{~nJ}$. Although the differences in the $P_{\mathrm{E}}$ values between the two modes are statistically significant (95\% confidence limits), these differences are not larger than by a factor 2 or 3. On the other hand, if $P_{\mathrm{E}}$ is considered as a function of the local incident energy density (abscissa $\mathrm{B}_{\mathrm{I}}, \mathrm{B}_{\mathrm{II}}$ ), then the dependence of $\boldsymbol{P}_{\mathrm{E}}$ differs by more than one order of magnitude for the two irradiation modes: Whereas in case of mode I irradiation, a marked percentage of cells with GCS 


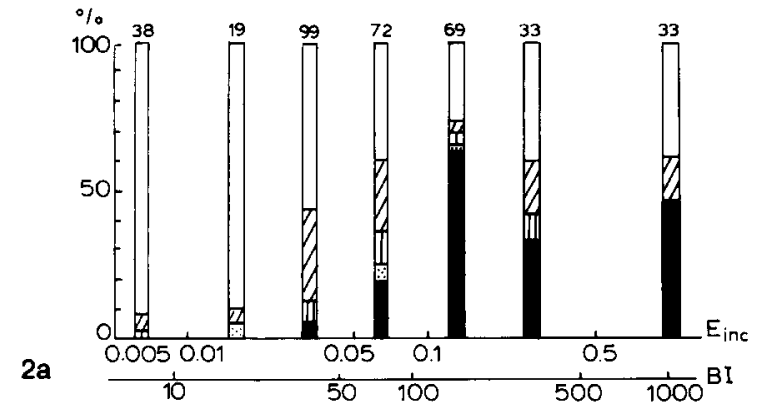

$2 b$

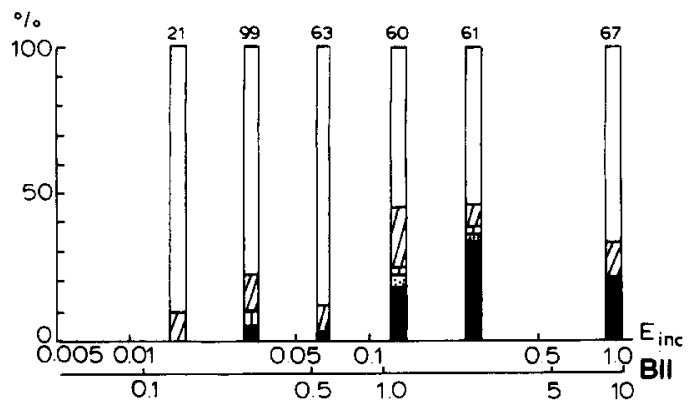

Fig. 2. Microirradiation of a small or of a large part of the nucleus and postincubation with $1 \mathrm{mM}$ caffeine: Variation of the incident UV energy. V79 cells were microirradiated 3-5 h following mitotic selection (synchronized cells). Then the cells were incubated with $1 \mathrm{mM}$ caffeine for $T=14 \mathrm{~h}$. (a) Effect of mode I irradiation (microirradiation of a randomly selected small part of the nucleus). Ordinate: percentage of metaphase figures, classes A-E: A, $\square ; \mathrm{B}, \mathbf{\square} ; \mathrm{C}, \mathrm{m} ; \mathrm{D}, \mathbf{\mathrm { v }} ; \mathrm{E}(\mathrm{GCS}), \mathbf{\square}$. Abscissa: $E_{\text {inc }}$ : Total incident UV energy per cell (nJ); $B_{\mathrm{I}}$ : Mean energy density $\left(\mathrm{J} / \mathrm{m}^{2}\right)$ in the irradiation field using mode I irradiation (C. Cremer et al., 1981b). In parentheses, the number of mitotic cells analyzed is given. (b) Effect of mode II irradiation (microirradiation of approximately the whole nucleus). Ordinate: denotation as in Fig. 2a. Abscissa: $E_{\text {inc }}$ : Total incident UV energy per cell (nJ); $B_{\mathrm{II}}$ : Mean energy density in the irradiation field using mode II irradiation (C. Cremer et al., 1981b). For other denotation see Fig. 2a. The differences in the maximum percentages of cells observed after mode I and II irradiation are slightly significant on the $95 \%$ confidence level (C. Cremer et al., 1980a).

was observed at energy densities between $100 \mathrm{~J} / \mathrm{m}^{2}$ and $1000 \mathrm{~J} / \mathrm{m}^{2}$, it was only between 1 and 10 $\mathrm{J} / \mathrm{m}^{2}$ in case of mode II irradiation. In this latter case, the range of energy densities was very similar to the range of energy densities which induced cells with GCS following whole cell irradiation of synchronized V79 cells and posttreatment with 1 mM caffeine (C. Cremer et al., 1981a). Similar results were obtained if the incubation time with caffeine was varied (Fig. 3). The differences in the percentage of cells with GCS were only slightly

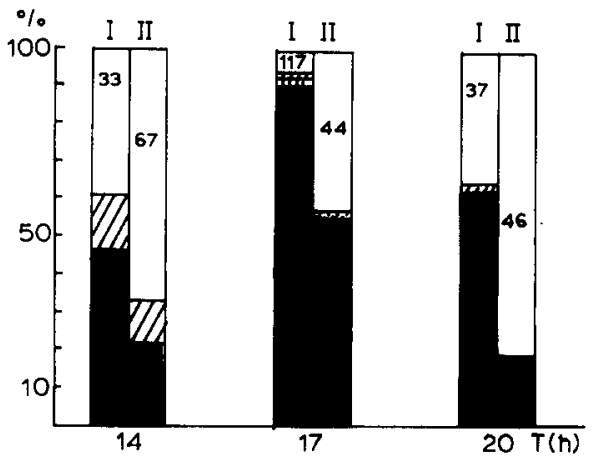

Fig. 3. Microirradiation of a small or of a large part of the nucleus and postincubation with $1 \mathrm{mM}$ caffeine: influence of incubation time. Synchronized V79 cells were microirradiated in the nucleus using either mode I or mode II; then the cells were incubated with $1 \mathrm{mM}$ caffeine (see Fig. 2). The total incident UV energy per cell was $1.0 \mathrm{~nJ}$. Ordinate: percentage of metaphase figures classes $\mathrm{A}-\mathrm{E}$ as denoted in Fig. 2; $\mathrm{Ab}$ scissa: incubation time with $1 \mathrm{mM}$ caffeine (h). The bars denoted as I, II represent the results of mode I and mode II irradiation, respectively. The arabic figures within the bars give the number of analyzed mitoses.

significant (95\% confidence limits) in spite of the large differences in energy densities between the two irradiation modes.

\section{(II) Microirradiation of interphase nuclei (mode I} and mode II) and postincubation with $2 \mathrm{mM}$ caffeine

In Fig. 4, the effect of different distributions of photolesions plus posttreatment with $2 \mathrm{mM}$ caffeine is presented.

Fig. 4a shows a result after microirradiation of synchronized cells with an incident energy $E_{\text {inc }}=$ $0.3 \mathrm{~nJ}$ and postincubation with $2 \mathrm{mM}$ caffeine for $T=14 \mathrm{~h}$. While the energy densities applied in mode I and mode II irradiation were varied by about two orders of magnitude (C. Cremer et al., $1981 b)$, no significant differences $(95 \%$ confidence limits) were observed for the percentages of cells with GCS. In addition, asynchronously growing cells were microirradiated in the nucleus, using either mode I or mode II irradiation (Fig. 4b). In all cases, the incident UV energy was $0.53 \mathrm{~nJ}$ per cell. Following irradiation, the cells were incubated with $2 \mathrm{mM}$ caffeine. Again, no significant differences were observed for the percentage of cells with GCS (Fig. 4b). 

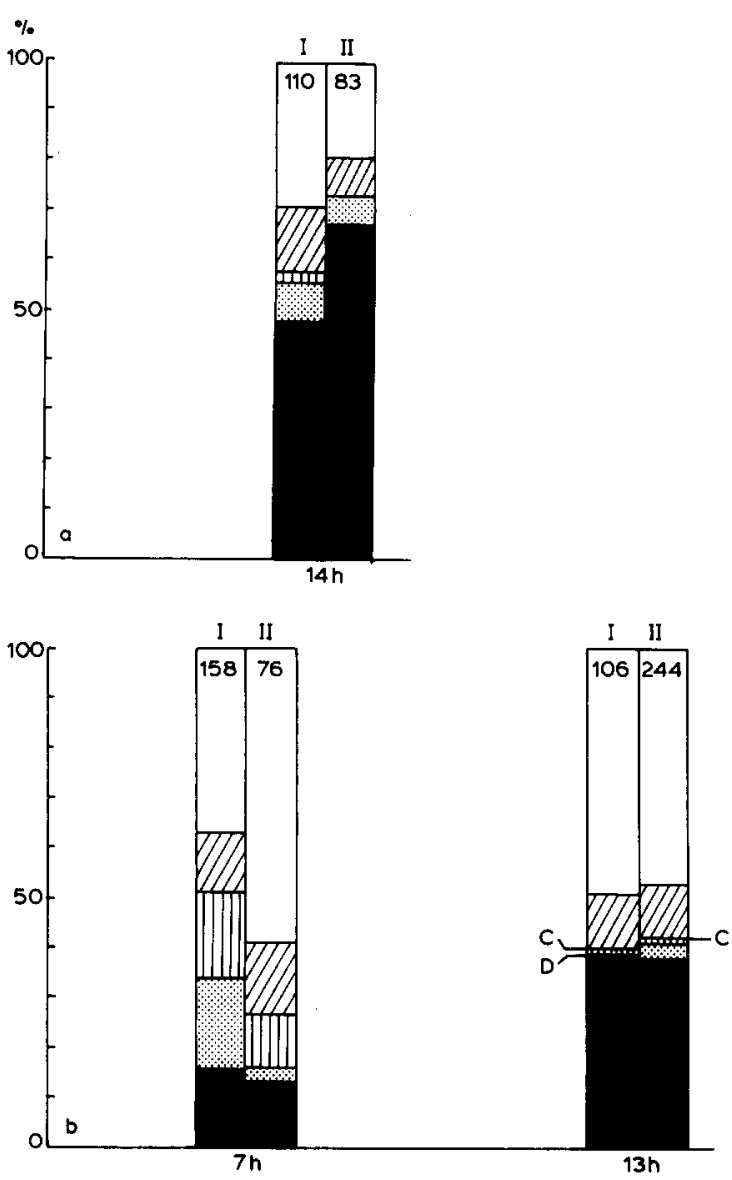

Fig. 4. Microirradiation of a small or of a large part of the nucleus and postincubation with $2 \mathrm{mM}$ caffeine. Asynchronously growing and synchronized V79 cells were microirradiated in the nucleus and postincubated with $2 \mathrm{mM}$ caffeine. The total incident UV energy was either focused to a randomly selected small part of the nucleus (mode I) or distributed over approximately the whole nucleus (mode II). The bars denoted as I, II represent the results of mode I and mode II irradiation, respectively. (a) Synchronized cells: The cells were microirradiated $3-5 \mathrm{~h}$ following mitotic selection. The incident UV energy was $0.3 \mathrm{~nJ}$. After irradiation, the cells were incubated for $T=14 \mathrm{~h}$ with caffeine, until chromosome preparation was made. Shown is the percentage of mitotic cells of classes A-E. (b) Asynchronous cells: The total incident UV energy was $0.53 \mathrm{~nJ}$ per cell. Ordinate: percentage of mitotic figures of classes A-E. Abscissa: incubation time with caffeine (h). For other denotation see Fig. 2.

\section{Discussion}

Different mechanisms are conceivable ( $T$. Cremer et al. 1981a; C. Cremer, 1981a) to explain how DNA photolesions introduced into a few interphase chromosomes by microirradiation mode I may trigger GCS not only in these irradiated chromosomes but also in other chromosomes containing no or only a few photolesions. Here, we restrict ourselves to a model which assumes the depletion of a factor pool. This model proposes the following events: In the presence of caffeine, drainage of a factor pool takes place when the number of factor-binding sites $N$ surpasses a threshold $N_{\mathrm{T}}$. Both DNA-replication points (number of points: $N_{0}$ ) and sites of daughter strand repair (number of sites: $N_{U V}$ ) are assumed to offer binding sites. This means that DNA photolesions have to be converted into factor-binding sites by semiconservative DNA replication. The model predicts that GCS is induced for $N=N_{0}+$ $N_{\text {UV }}>N_{\mathrm{T}}$ (threshold) and it is fully compatible with a large body of experimental observations (C. Cremer et al., 1981a; T. Cremer et al., 1981a). Another conclusion of crucial importance is the prediction that GCS depends only on the total number of daughter strand-repair sites but not on their distribution in the chromatin.

Our model does not include any prejudice concerning the nature of such a factor except for the assumption that factor molecules should be diffusible in the nuclear sap. A number of possible candidates may be considered including any enzyme acting both at DNA replication points and sites of daughter strand repair (Tomilin and Svetlova, 1974; Sedgwick and Bridges, 1974). The effect of caffeine then might be simply due to the fact that it inhibits the timely elimination of the sites of daughter strand repair which are continuously produced by the replication of damaged DNA strands. This might critically increase the level of factor-binding sites.

Another possible mode of action is the ability of caffeine to activate new origins for DNA synthesis (Lehmann, 1972; Tatsumi and Strauss, 1979; Painter, 1980) and prevent the inhibition of replicon initiation in mutagen-treated cells. This hypothesis is consistent with the finding that following UV irradiation of V79 cells and posttreatment with caffeine, the duration of S-phase was observed to be reduced (C. Cremer et al., 1981a).

Under the microirradiation conditions used here, the approximation may be made that the initial number of DNA photolesions $N_{\mathrm{UV}}^{0}$ is di- 
rectly proportional to the incident UV energy and independent of its distribution within the nucleus. The number of DNA photolesions still present at the time of replication (these DNA photolesions are to be converted into daughter strand-repair sites) depends critically on the efficiency of excision-repair processes. If the efficiency of excision repair is similar after both modes of microirradiation, then the model predicts similar yields of cells with GCS.

This prediction is fulfilled almost perfectly in case of microirradiation plus postincubation with $2 \mathrm{mM}$ caffeine (Fig. 4). After microirradiation plus posttreatment with $1 \mathrm{mM}$ caffeine (Figs. 2, 3), a similar dependence of $P_{E}$ on the incident UV energy was observed for both irradiation modes while the corresponding energy densities differed by two orders of magnitude.

To summarize, the results indicate that the percentage of cells with GCS depends on the total number of DNA photolesions rather than on their spatial distribution in the chromatin of a cell. The deviation from an ideal distribution independence observed in the case of $1 \mathrm{mM}$ caffeine may be explained by both technical and biological reasons. For technical reasons, the irradiation field in mode II experiments probably did not exactly fit the nuclear area in all cases but sometimes included a small part of cytoplasm besides the nuclei. Thus the average incident UV energy applied to the nucleus might have been somewhat smaller in mode II as compared with mode I experiments. We have shown previously that microirradiation of the cytoplasm of interphase nuclei is not effective in the induction of chromosome shattering (C. Cremer et al., 1981a). For biological reasons, the kinetics by which daughter strand-repair sites are produced in damaged DNA strands might differ somewhat in nuclei exposed to mode I and mode II irradiation, respectively. This effect might be more pronounced in the case of a lower concentration of caffeine.

Whatever the correct interpretation of the difference may be, the results of our microbeam studies were completely unexpected in the light of previous models explaining the induction of chromosome damage after UV irradiation and caffeine posttreatment solely as a result of the interference of caffeine with daughter strand repair (Nilsson and Lehmann, 1975; Kihlman, 1977).

In the majority of cases, cells with GCS displayed a morphology similar to premature chromosome condensation (C. Cremer et al., 1980a; T. Cremer et al., 1981a). Although it has been shown (C. Cremer and Gray, 1982) that GCS cells have the same DNA content as untreated cells in G2 phase and mitosis, the factor-depletion model does not rule out that failure of normal chromosome condensation indeed plays a major role in the induction of GCS. This view is consistent with the recent finding (our own unpublished results) that cells with GCS are able to form interphase cells with only a few and relatively large micronuclei.

It has been postulated (Gonzáles-Fernández et al., 1985) that during late G2 and prophase, chromatin condensation could lead to the induction of chromosome damage from pre-existing DNA lesions which would be readily repaired by a G2prophase repair mechanism. In the presence of caffeine, this activity is inhibited, leading to the formation of chromosomal aberrations. Furthermore, it has been proposed (Painter and Young, 1980; Kihlman et al., 1982; Lau and Pardee, 1982) that instead of directly inhibiting DNA-repair pathways, caffeine prevents damaged cells from delay in the G2 phase (Barranco and Humphrey, 1970; Tobey, 1975). As a consequence, caffeinetreated cells may be induced to undergo mitosis before they can repair the lesions in their DNA. This may result in the formation of shattered chromosomes.

It should be pointed out that each "G2 phase" model by itself may explain how pre-existing DNA lesions are converted into chromosome damage. They fail, however, to explain why GCS is frequently observed in the case of microirradiation of a small part of the nucleus (C. Cremer et al., 1981a), introducing DNA photolesions in a few chromosomes only. In this case, the chromosome alterations are expected to be restricted to those few chromosome regions containing DNA photolesions, i.e. no GCS should be observed. In particular, the two "G2 phase" models do not account for the finding that the percentage of cells with GCS depends on the total number of DNA photolesions rather than on their distribution in the nucleus.

In addition, we have shown (C. Cremer et al., 
1980a) that the percentage of cells with GCS following UV irradiation and posttreatment with caffeine can be significantly reduced by the addition of small amounts of deoxyribonucleosides, without affecting the length of G2+ prophase. This indicates that besides a caffeine-induced reversion of $\mathrm{G} 2$ delay, other factors may be important.

To summarize, the factor-depletion model presented here accounts for a large body of experimental findings which are difficult to explain by current daughter strand-repair models and/or " $\mathrm{G} 2$ phase" models.

We assume that indirect effects as predicted by the factor depletion model are not limited to the induction of GCS by ultraviolet light and caffeine but may play a role also in the induction of GCS by chemical mutagens and caffeine.

\section{Acknowledgements}

This work was performed by grants from the Deutsche Forschungsgemeinschaft.

The skilful technical assistance of Mr. Jürgen Zimmer is gratefully acknowledged.

\section{References}

Barranco, S.C., and R.M. Humphrey (1970) A time-specific effect of UV irradiation on cells progressing from $\mathrm{G} 2$ into metaphase, Mutation Res., 9, 524-526.

Brenner, S.L., L.-H. Liaw and M.W. Berns (1980) Laser microirradiation of kinetochores in mitotic PtK2 cells, Cell Biophys., 2, 139-151.

Cornelis, J.J., and M. Errera (1980) Immunocytochemical detection of pyrimidine dimers in situ, in: E.C. Friedberg and P.C. Hanawalt (Eds.), DNA Repair, a Laboratory Manual of Research Procedures, Vol. I, part A, pp. 31-44.

Cremer, C., and J.W. Gray (1982) DNA content of cells with generalized chromosome shattering induced by ultraviolet light plus caffeine, Mutation Res., 94, 133-142.

Cremer, C., C. Zorn and T. Cremer (1974) An ultraviolet laser microbeam for $257 \mathrm{~nm}$, Microscop. Acta, 75, 331-337.

Cremer, C., T. Cremer, C. Zorn and L. Schoeller (1976) Effects of laser-UV-microirradiation $(\lambda=2573 \AA)$ on proliferation of Chinese hamster cells, Radiat. Res., 66, 106-121.

Cremer, C., T. Cremer and M. Simickova (1980a) Induction of chromosome shattering and micronuclei by ultraviolet light and caffeine, I. Temporal relationship and antagonistic effects of the four deoxyribonucleosides, Environ. Mutagen., 2, 339-351.

Cremer, C., T. Cremer, M. Fukuda and K. Nakanishi (1980b) Detection of laser-UV-microirradiation induced DNA pho- tolesions by immunofluorescent staining, Hum. Genet., 54, 107-110.

Cremer, C., T. Cremer, C. Zorn and J. Zimmer (1981a) Induction of chromosome shattering by ultraviolet light and caffeine: comparison of whole-cell and partial-cell irradiation, Mutation Res., 84, 331-348.

Cremer, C., T. Cremer and G. Jabbur (1981b) Laser-UV-microirradiation of Chinese hamster cells: The influence of the distribution of photolesions on unscheduled DNA synthesis, Photochem. Photobiol., 33, 925-928.

Cremer, C., T. Cremer and J.W. Gray (1982) Induction of chromosome damage by ultraviolet light and caffeine: Correlation of cytogenetic evaluation and flow karyotype, $\mathrm{Cy}$ tometry, 2, 287-290.

Cremer, C., T. Cremer, L. Hens, H. Baumann, J.J. Cornelis and K. Nakanishi (1983) UV-micro-irradiation of the Chinese hamster cell nucleus and caffeine post-treatment, Immunocytochemical localization of DNA photolesions in cells with partial and generalized chromosome shattering, Mutation Res., 107, 465-476.

Cremer, T., C. Cremer, J. Zimmer and C. Zorn (1980) UV-microirradiation of Chinese hamster cells and posttreatment with caffeine: Indication for clastogenic effects remote from the irradiation site, in: $\mathrm{H}$. Altmann, E. Riklis and $\mathrm{H}$. Slor (Eds.), DNA Repair and Late Effects, Nuclear Research Center, Negev, Israel, pp. 53-62.

Cremer, T., S. Peterson, C. Cremer and M.W. Berns (1981a) Laser microirradiation of Chinese hamster cells at wavelength $365 \mathrm{~nm}$ : Effects of psoralen and caffeine, Radiat. Res., 85, 529-543.

Cremer, T., A. Turner, L.-H. Liaw and M.W. Berns (1981b) Giant cell formation produced by laser microbeam irradiation of chromatin in Chinese hamster cells, Exp. Cell Res., 134, 49-63.

Cremer, T., C. Cremer, H. Baumann, E.-K. Luedtke, K. Sperling, V. Teuber and C. Zorn (1982a) Rabl's model of the interphase chromosome arrangement tested in Chinese hamster cells by premature chromosome condensation and laser-UV-microbeam experiments, Hum. Genet., 60, 46-56.

Cremer, T., C. Cremer, T. Schneider, H. Baumann, L. Hens and M. Kirsch-Volders (1982b) Analysis of chromosome positions in the interphase nucleus of Chinese hamster cells by laser-UV-microirradiation experiments, Hum. Genet., 62, 201-209.

Cremer, T., H. Baumann, K. Nakanishi and C. Cremer (1984) Correlation between interphase and metaphase chromosome arrangements as studied by laser-UV-microbeam experiments, Chromosomes Today, 8, 203-212.

González-Fernández, A., P. Hernández and J.F. López-Sáez (1985) Effect of caffeine and adenosine on G2 repair: mitotic delay and chromosome damage, Mutation Res., 149, 275-281.

Hens, L., H. Baumann, T. Cremer, A. Sutter, J.J. Cornelis and C. Cremer (1983) Immunocytochemical localization of chromatin regions UV-microirradiated in S-phase or anaphase: evidence for a territorial organization of chromosomes during the cell cycle of cultured Chinese hamster cells, Exp. Cell Res., 149, 257-269. 
Kihlman, B.A. (1977) Caffeine and Chromosomes, Elsevier, Amsterdam.

Kihlman, B.A., and A.T. Natarajan (1984) Potentiation of chromosomal alterations by inhibitors of DNA repair, in: A. Collins, C.S. Downes and R.T. Johnson (Eds.), DNA Repair and Its Inhibition, Nucleic Acids Symp. Ser. No. 13, IRL Press, Oxford, pp. 319-339.

Kihlman, B.A., S. Sturelid, B. Hartley-Asp and K. Nilsson (1974) The enhancement by caffeine of the frequencies of chromosomal aberrations induced in plant and animal cells by chemical and physical agents, Mutation Res., 26, 105-122.

Kihlman, B.A., K. Hansson and H.C. Andersson (1982) The effects of post-treatments with caffeine during $S$ and $G 2$ on the frequencies of chromosomal aberrations induced by thiotepa in root tips of Vicia faba and in human lymphocytes in vitro, Mutation Res., 104, 323-330.

Lau, C.C., and A. Pardee (1982) Mechanism by which caffeine potentiates lethality of nitrogen mustard, Proc. Natl. Acad. Sci. (U.S.A.), 79, 2942-2946.

Lehmann, A.R. (1972) Effect of caffeine on DNA synthesis in mammalian cells, Biophys. J., 12, 1316-1325.

Moreno, G., and Ch. Salet (1974) Unscheduled DNA synthesis after ultraviolet microirradiation of the cell nucleus, Radiat. Res., 58, 52-59.

Nilsson, K., and A.R. Lehmann (1975) The effect of methylated oxypurines on the size of newly-synthesized DNA and on the production of chromosome aberrations after UVirradiation in Chinese hamster cells, Mutation Res., 30, $255-266$.

Painter, R.B. (1980) Effect of caffeine on DNA synthesis in irradiated and unirradiated mammalian cells, Mol. Biol., 143, 289-301.

Painter, R.B., and B.R. Young (1980) Radiosensitivity in ataxia-telangiectasia: A new explanation, Proc. Natl. Acad. Sci. (U.S.A.), 77, 7315-7317.

Raith, M., T. Cremer, C. Cremer and G. Speit (1984) Sister chromatid exchange (SCE) induced by laser-UV-microirradiation: correlation between the distribution of photolesions and the distribution of SCEs, in: R.R. Tice and A. Hollaender (Eds.), Sister Chromatid Exchanges, Plenum, New York, pp. 181-197.
Rappold, G.A., T. Cremer, C. Cremer, W. Back, J. Bogenberger and H.J. Cooke (1984) Chromosome assignment of two cloned DNA probes hybridizing predominantly to human sex chromosomes, Hum. Genet., 65, 257-261.

Roberts, J.J. (1984) Mechanism of potentiation by caffeine of genotoxic damage induced by physical and chemical agents, in: A. Collins, C.S. Downes and R.T. Johnson (Eds.), DNA Repair and its Inhibition, Nucleic Acids Symp. Ser. No. 13, IRL Press, Oxford, pp. 193-215.

Schardin, M., T. Cremer, H.D. Hager and M. Lang (1985) Specific staining of human chromosomes in Chinese hamster $\times$ man hybrid cell lines demonstrates interphase chromosome territories, Hum. Genet., 71, 281-287.

Sedgwick, S.G., and B.A. Bridges (1974) Requirement for either DNA polymerase I or DNA polymerase III in postreplication repair in excision-proficient Escherichia coli, Nature (London), 249, 348-349.

Setlow, R.B. (1966) Cyclobutane-type pyrimidine dimers in polynucleotides, Science, 153, 379-386.

Stack, S.M., D.B. Brown and W.C. Dewey (1977) Visualization of interphase chromosomes, J. Cell Sci., 26, 281-299.

Steward, D.L., and R.M. Humphrey (1966) Induction of thymine dimers in synchronized populations of Chinese hamster cells, Nature (London), 212, 298-300.

Tatsumi, K., and B.S. Strauss (1979) Accumulation of DNA growing points in caffeine-treated human lymphoblastoid cells, J. Mol. Biol., 135, 435-449.

Tobey, R.A. (1975) Different drugs arrest cells at a number of distinct stages in G2, Nature (London), 254, 245-247.

Tomilin, N.V., and M.P. Svetlova (1974) On the mechanism of postreplication repair in Escherichia coli cells: The role of polymerase III, FEBS Lett., 43, 185-188.

Zorn, C., T. Cremer, C. Cremer and J. Zimmer (1976) LaserUV-micro-irradiation of interphase nuclei and posttreatment with caffeine: A new approach to establish the arrangement of interphase chromosomes, Hum. Genet., 35, 83-89.

Zorn, C., C. Cremer, T. Cremer and J. Zimmer (1979) Unscheduled DNA synthesis after partial UV-irradiation of the cell nucleus. Distribution in interphase and metaphase, Exp. Cell Res., 124, 111-119. 